PROBLEMS

OF MANAGEMENT

IN THE $21^{\text {st }}$ CENTURY

Volume 8, 2013

\title{
THE IMPACT OF INCENTIVES ON
} PRODUCTIVITY OF FIRMS IN GHANA: A CASE STUDY OF GHANA AIRPORT COMPANY LIMITED

\author{
Godson Ahiabor \\ Central University College, Tema, Ghana \\ E-mail: gkhiabor@yahoo.com
}

\begin{abstract}
The study investigates the impact of incentives on the productivity of firms in Ghana. The study had the following objectives: to establish the relationship between incentives and higher productivity among workers, to find out any relationship between motivational factors and work of staff, and to determine how incentives influence workers approach to work and their performance. To achieve these goals, a questionnaire was designed based on the objectives. The completed questionnaires were processed and analyzed using Simple Percentage and Frequency. The findings of this study revealed that there was a positive relationship between incentives and productivity, alongside monetary incentives, another key factor in motivating employees is to involve them in the process aimed at attaining organizational effectiveness because without their co-operation the organization cannot perform. The study concluded that non monetary factors like health, equipment use among other things counted more than monetary rewards. The study recommends the establishment of a unit to look at issues of incentives that will enhance productivity.
\end{abstract}

Key words: incentives, productivity, impact, firms and relationship.

\section{Introduction}

In light of today's business conditions, motivating people to give their best has become more crucial than ever, because of stiff competition and economic uncertainties. The factor that can set apart an organization in this turbulent environment be it in the public or private sectors is its people, therefore establishing and maintaining a stable workforce is a major concern of human resource department. Worker motivation is essential since there is a direct relationship between motivation and productivity. Only through motivation, can managers' help their employees generate the excellent performance that enables companies or organizations to boost profitability and survive, even thrive during tough times.

\section{Problem of Research}

Ghana is reputed to be a conducive environment for investments. Recent exploratory works have indicated that the country has a large reserve of oil. The country therefore has the potential of becoming a leading industrialized (if the potential is properly harnessed) nation in the world in the not-too-distant future due to this natural endowment.

The current state of affairs in the nation in general as relating to the workforce motivation makes it necessary to temper this optimism with caution. "The workers are on strike 
again." "Over what?" "They are asking for another pay rise after the one granted just a few months ago." "What more do they want?" These statements and comments and many similar ones are reported frequently in the dailies and are commented upon by watchers of development in various industry and service organizations. The questions are often asked as to what workers in general want from their employers. Can there be an end to the clam for increases in wages? Why do workers work and what induces them to give of their best? Money only plays the role of common denominator of all things. There is a general notion that if only management can identify other things that can motivate the workforce apart from money, perhaps there will be a dramatic reduction in the demand by workers for pay rises. Less time will be spent on the annual ritual of management/workers' union negotiation meetings (James, 2011).

The general problem inherent in the organizational set up is low salaries, irregular promotional structure and lack of recognition of workers' achievements. All these tend to dampen workers morale and consequently affect their productivity. The aim of this research therefore is to find out the type of incentive package that needs to be given to workers and whether workers, given the right incentives other than money can put in their best to contribute to the productivity and growth of the organizations to achieve the corporate objectives. Based on problem of discussion, this study seeks to look at the impact of incentives on productivity of firms in Ghana.

\section{Research Focus}

Incentives are things that motivate an individual to perform an action. They may be used to incite or tend to incite to action or greater effort, as a reward offered for increased productivity. It can also be said to be a factor that motivates a person to achieve a particular goal. Incentives are therefore motivations for work. They could be monetary rewards or non monetary rewards. Incentives could be categorized as compensation incentives which may include items such as pay raises, bonuses, profit sharing, signing bonus, and stock options, recognition incentives which may include actions such as thanking employees, praising employees, presenting employees with a certificate of achievement, or announcing an accomplishment at a company meeting. Rewards incentives which may also include items such as gifts, monetary rewards, service award presents, and items such as gift certificates and appreciation incentives which includes such happenings as company parties and celebrations, company paid family activity events, ice cream socials, birthday celebrations, sporting events, paid group lunches, and sponsored sports teams (Heathfield, 2013).

Productivity on the other hand is the output per head. Productivity is linked with incentives or motivation. Gibbons (2006) did a research on incentives and came to the conclusion that although people have satisfactory salaries, some nonfinancial motivators are more effective than extra cash in building long-term employee engagement in most sectors, job functions. This means that people have shifted from the notion that monetary incentive is the main form of incentive for productivity. McKinsey Quarterly, survey revealed that non monetary motivators or incentives such as praises from immediate managers, leadership attention, and a chance to lead projects or task forces, rated higher than the three highest-rated financial incentives: cash bonuses, increased base pay, and stock or stock options (McKinsey Quarterly Survey, 2009).

Although non financial incentives are cost effective, yet many organizations hesitate to use it due to the traditional managerial wisdom: money is what really counts and also requires time commitment from managers to enforce it. According to Shanks (2012) which was cited in (Morse, 2003). Extrinsic rewards includes money, workers union negotiation meetings (Badu, 2010 benefits, flexible schedules, job responsibilities and duties, promotions, change in status, supervision of others, praise and feedback and a good boss serve as incentives for employees to increase their productivity. These emphasis that there are various forms of incentives that affect productivity. Cappelli and Neumark (2000) indicates that there might be synergies between 
Godson AHIABOR. The Impact of Incentives on Productivity of Firms in Ghana: A Case Study of Ghana Airport Company Limited

PROBLEMS

OF MANAGEMENT

IN THE $21^{\text {st }}$ CENTURY Volume 8,2013

high performance at the workplace such as teamwork, employee share ownership, profit sharing, and employee participation that should be taken into account empirically. Zwick (2004) in his research found a positive link between incentive and productivity which is based on trust and cooperation in Germany and beneficial to the returns of a participative labor organization. Other researchers have suggested that monetary incentives are not effective measures to boost productivity (Elke \& Zwick, 2008). It appears therefore that monetary incentives may not be the best way of increasing productivity but non-monetary incentives should be considered.

The main aim of the study is to investigate the impact of incentives on productivity of Ghana Airport Company Limited.

Specifically, the study seeks to:

1. Determine how incentives influence the staff of this company approach to work

2. Find out any relationship between motivational/incentives factors and the performance of staff or employees of this company

3. Establish whether incentives has any influence on the staff of this company

\section{Research Questions}

The research will attempt to retain answers to the question agitating the minds of management of organizations as to what to do to adequately motivate workers to contribute their quota to their company's productivity and growth. The study will answer the following research questions:

1. Is there any relationship between incentives and higher performance productivity?

2. Is there any relationship between motivational/incentives factors and attitude to the work of staff of the organization?

\section{Methodology of Research}

\section{General Background of Research}

Research work most often than not is appraised based on the quality and accurateness of the analysis and information it provides at the end. However, this is dependent on the nature of data collected during the research. The methodology highlighted on the tools or techniques for research design, data collection, the population and sampling techniques, and data sources, data collection instruments, and data analysis plan.

\section{Data Collection}

Data collection in a research is the stage where the necessary data useful for the purposes and objectives of the research are gathered from the field. The ways for gathering these data is what is termed data collection methods. Two main sources of data were used for the research work; primary sources and secondary sources. The methods used in collecting primary data include interview, questionnaire, and observations. The study made use of primary data which is the analysis stage. Secondary source includes data from published and unpublished books, magazines, journals, websites etc.

\section{Sample of Research}

Sample size of sixty (60) was selected using the stratified sampling method. The choice of this sampling procedure was because it has no personal bias and it is scientific and objective. Under this method, the researcher categorized the staff of Ghana Airports Company Limited 
according to their already existing departments namely (Human Resources, Operations, Marketing and security departments).

\section{Data Analysis}

The analysis of the data collected was done at the end of the data collection. The responses were classified and summarized on the basis of the information provided by the respondents. The analysis was done using both qualitative and quantitative tools. With the quantitative tools, the current version of Statistical Product and Services Solution (SPSS) data analysis programme, Microsoft excel, absolute figures, tables, percentages, and statistical tools such as graphs, charts, were used, whereas qualitative made use of descriptions, analysis of feedback from interview.

\section{Results of Research}

The respective respondents were analyzed by the researchers with the aid of tables, bar chart and pie charts. In all, a total of seventy (70) questionnaires were issued to employees of Ghana Airport Company Limited unfortunately sixty (60) responded and returned the answered questionnaire. The researchers based their presentation on the major activities used in the questionnaires. The data generated in this study were analyzed and the findings are discussed under this heading according to the various research questions that were formulated to guide the study.

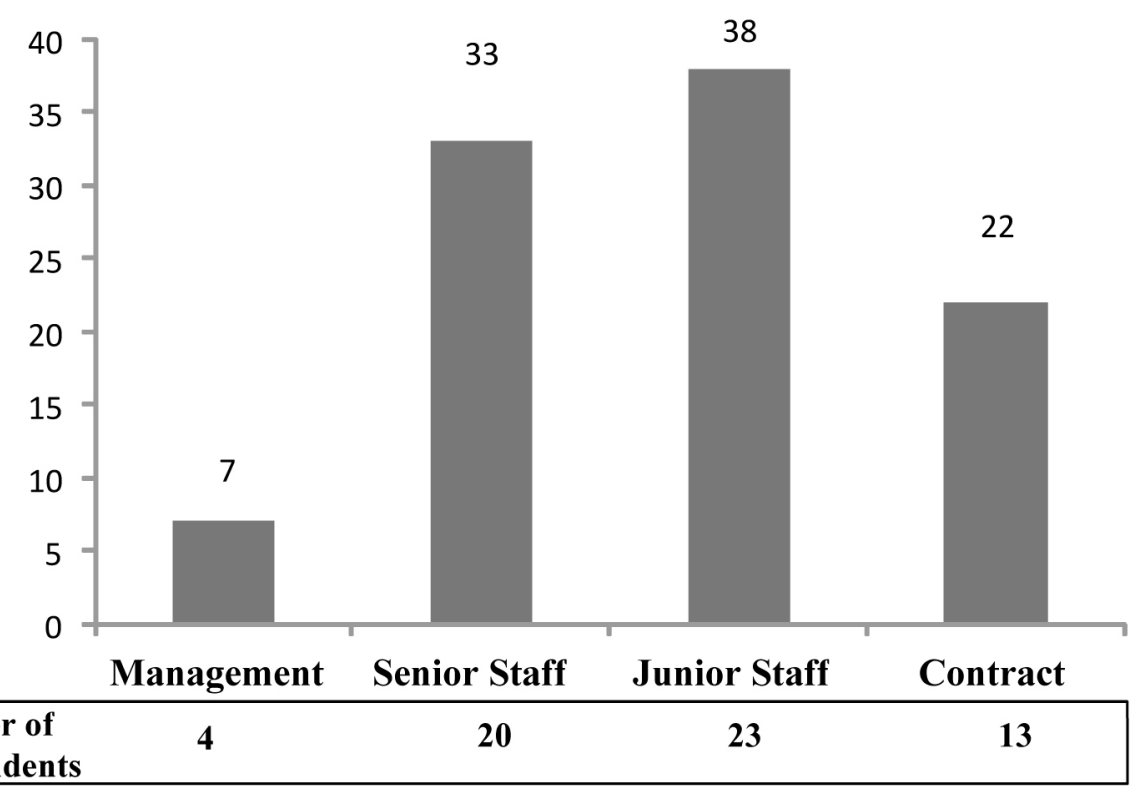

Source: Field Survey, 2013

\section{Figure 1: Staff category.}

Figure 1 represents the staff category of respondents. 23 representing $38 \%$ which forms the majority were junior workers, 20 representing 33\% were senior workers, 13 representing $22 \%$ were contract base employers and 4 representing $7 \%$ forming the minority were those in management position as it has been illustrated in the figure below. This shows that those in the 
Godson AHIABOR. The Impact of Incentives on Productivity of Firms in Ghana: A Case Study of Ghana Airport Company Limited

PROBLEMS

OF MANAGEMENT

IN THE $21^{\text {st }}$ CENTURY

Volume 8, 2013

management position did not get time to answer the researchers' questions and as such did not return the questionnaire. It may have slight effect on the research work.

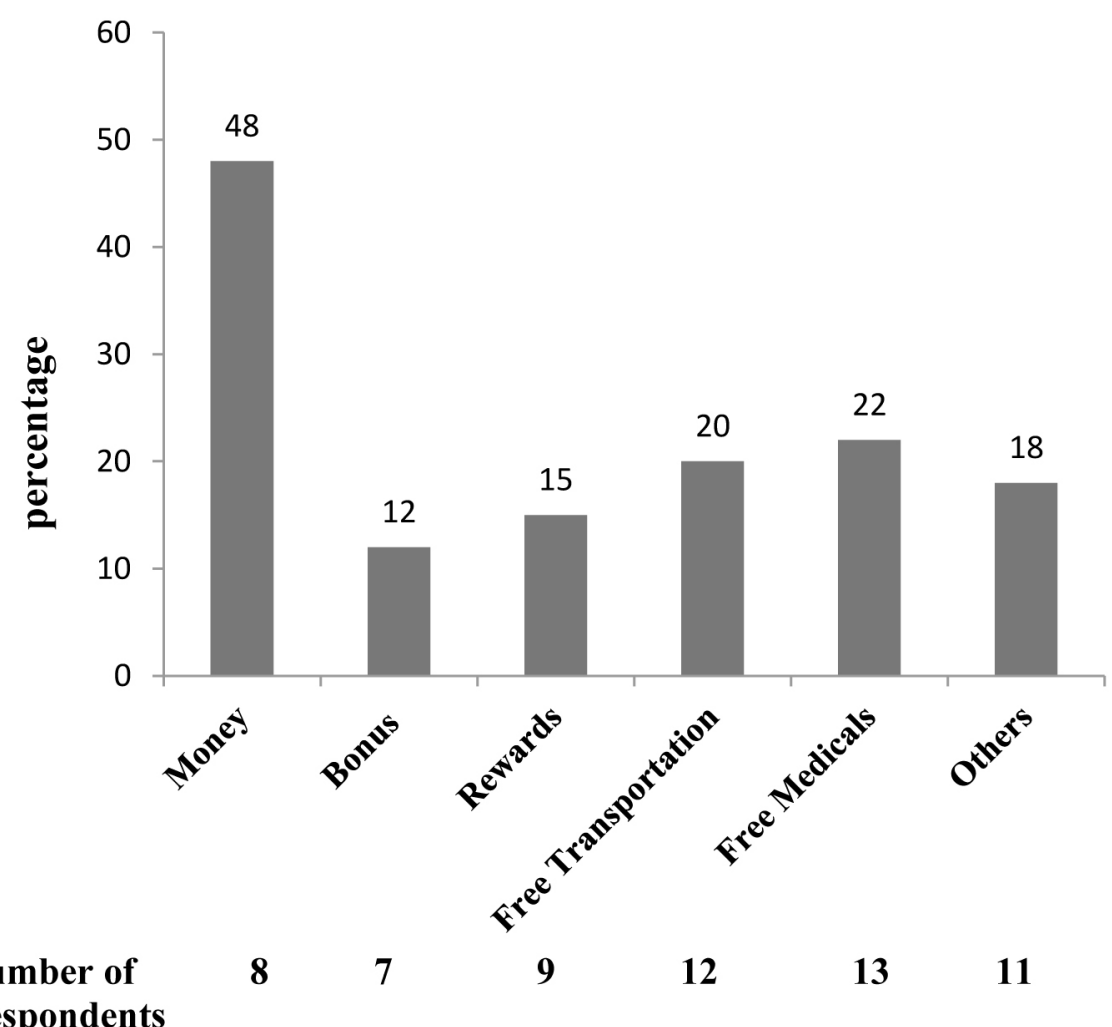

Source: Field Survey, 2013

\section{Figure 2: What is the first word that comes to mind when you think of incen-} tives.

The Figure 2 indicates when respondents were posed with open-ended questions as to what come to mind when they think of incentives. 13 representing $22 \%$ of the respondents mention free medical representing majority, 12 representing 20\% said free transportation, 11 representing $18 \%$ mention others, 9 representing $15 \%$ said rewards, 8 representing $13 \%$ said money and 7 representing $12 \%$ said bonus are terms as incentives. From these, it indicates that the majority of workers are thinking of receiving free medical care and they believe if they receive this kind of incentives as they know it will influence their performance level as the research question try to establish. 
Table 1. Incentives given to employees exerts influence on their performance.

\begin{tabular}{lcc}
\hline Statement & Number of Respondents & Percentage \\
\hline Strongly agree & 48 & 80 \\
Agree & 7 & 12 \\
Undecided & 2 & 3 \\
Disagree & 3 & 5 \\
Strongly disagree & - & - \\
\hline Total & 60 & 100 \\
\hline
\end{tabular}

Source: Field Survey, 2013

Table 1 indicates respondents' responds to the question being asked. 48 representing $80 \%$ of the majority strongly agreed to the statement. 7 representing $12 \%$ agreed to the statement, 2 representing 3\% were undecided and 3 representing 5\% disagree to the statement.

The finding from this study as it relates to research question one, showed that there are incentives or factors that motivate and exerts some kind of influence in relation to workers productivity and performance. The major finding of this study was that $80 \%$ of the respondents indicated that incentives given to workers influence their performance. The result also showed with an appreciable difference in the amount of consideration or adequate incentives their performance will increase more.

Table 2. Incentives given to employees to enable them to have a positive attitude to work.

\begin{tabular}{lcc}
\hline Statement & Number of Respondents & Percentage \\
\hline Strongly agree & 40 & 67 \\
Agree & 18 & 30 \\
Undecided & 2 & 3 \\
Disagree & - & - \\
Strongly disagree & - & - \\
\hline Total & 60 & 100 \\
\hline
\end{tabular}

Source: Field Survey, 2013

In Table 2 indicates respondents' response to the above question. 40 representing $67 \%$ of the respondents strongly agree, 18 representing 30\% agree, and 2 representing $3 \%$ were undecided. It reveals that if a majority of the workers strongly agree with the notion then it tells that incentives play a major role in motivating employees and it enable them to have a positive attitude towards work and intend achieve higher goals. In any organization, incentives work because employees are then goal-driven and push themselves to achieve their targets because they know what they will receive after they or the organization achieve it set target. 
PROBLEMS OF MANAGEMENT IN THE $21^{\text {st }}$ CENTURY $\begin{array}{r}\text { Volume 8, 2013 } \\ \hline 12\end{array}$

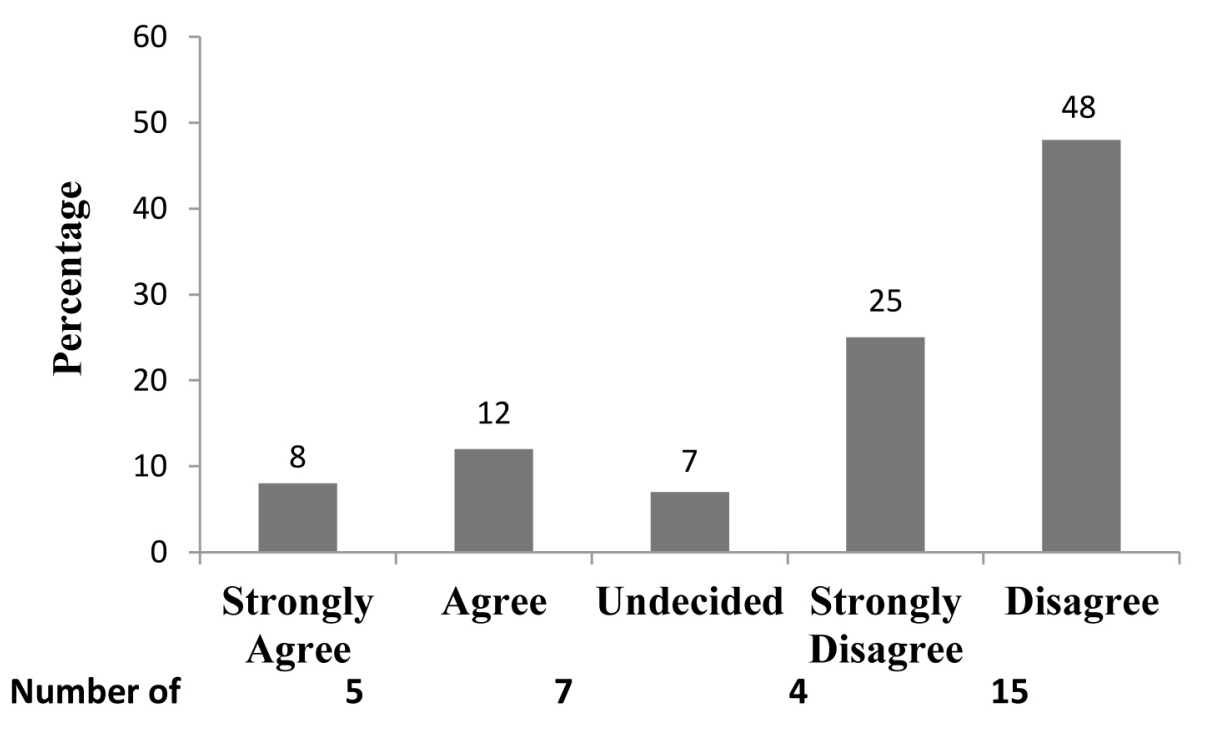

Source: Field Survey, 2013

Figure 3: Only monetary rewards can bring out the best in workers.

In Figure 3 respondents were asked if it is only monetary rewards that can bring out the best in workers. $8 \%$ strongly agree, $12 \%$ agreed, $7 \%$ were undecided, $25 \%$ disagree and $48 \%$ representing the majority disagree to the question asked. With reference to the question, it is not only monetary rewards that can bring out the best in workers as it has been indicated $48 \%$ of the respondents disagree as shown in the figure below. This shows that there are other factors or incentives that workers look out.

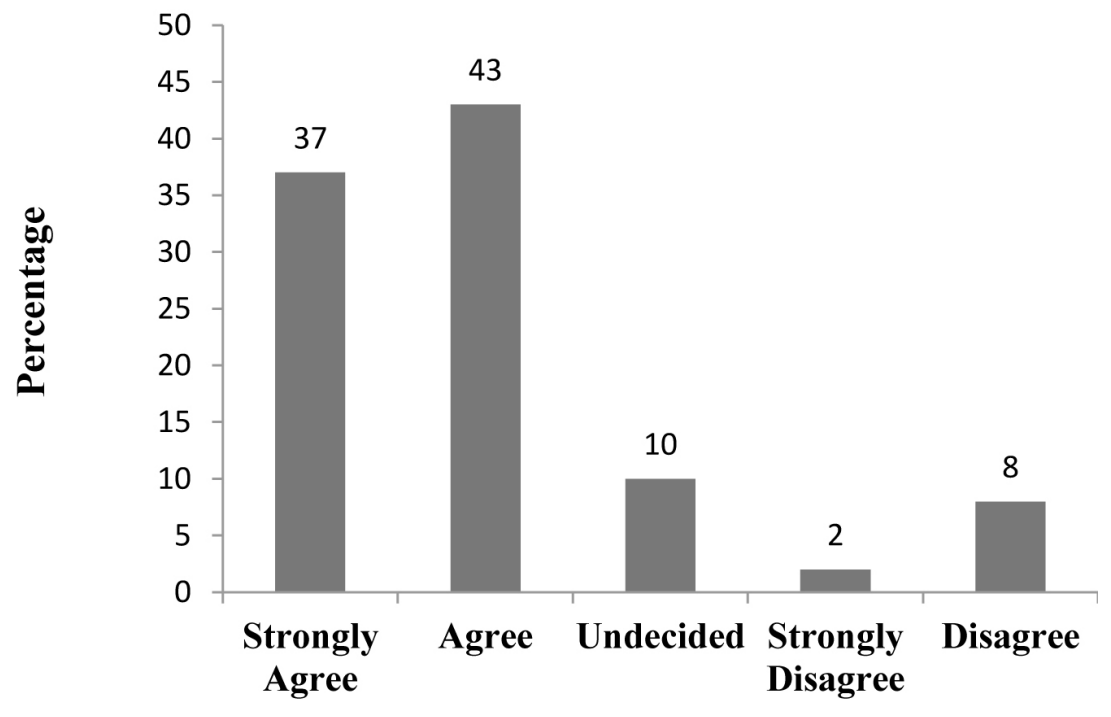

Number of

22

26

6

1

5

Source: Field Survey 2013

Figure 4: The current confidence of workers to put more effort to perform better in any job is due to the incentives given. 
In Figure 4 respondents' response on the question above are that 26 representing $43 \%$ of the sampled population agrees, which also forms the majority, 22 representing $37 \%$ strongly agree, 6 representing 10\% were undecided, 5 representing 8\% disagree and 1 representing $2 \%$ of the minority strongly disagree to the notion. Its current confidence of workers is as a result of incentives given because the majority of the respondents agrees with the notion which makes the response rate to these $100 \%$.

Table 3. With work appraisal and other non-monetary incentives have been an important way which has helped me to continuously improve my performance.

\begin{tabular}{lcc}
\hline Statement & Number of Respondents & Percentage \\
\hline Strongly agree & 27 & 45 \\
Agree & 32 & 53 \\
Undecided & 1 & 2 \\
Disagree & - & - \\
Strongly disagree & - & - \\
\hline Total & 60 & 100 \\
\hline
\end{tabular}

Source: Field Survey 2013

The Table 3 indicates respondents' response on the question above. 32 representing 53\% of the sampled population agrees forming the majority, 27 representing $45 \%$ strongly agree, 1 representing $2 \%$ of the minority were undecided to the notion. It reveals that with workers appraisals and other non-monetary incentives such as free transportation for workers. It improves their performance level and hence profitability.

\section{Discussion}

From the research respondents were asked what the incentive were, they mention money, bonus, reward, free transportation, free medicals and others. This can be classified as both monetary and non monetary. Some of these things mention can be found in McKinsey (2009) who talks about intrinsic and extrinsic incentives. Other findings from the work revealed that incentives influences performance and in this case positively and this conforms to literature as stated by Zwick (2004) in his research found a positive link between incentive and productivity which is based on trust and cooperation in Germany and beneficial to the returns of a participative labor organization. Furthermore the work revealed that monetary rewards were not the only way to bring out the best in a worker but non monetary measures.

Other researchers have suggested that monetary incentives are not effective measures to boost productivity (Elke \& Zwick, 2008). From the findings it is clear that incentives have positive effects on productivity however non monetary incentives appear to have more weight than monetary incentives.

\section{Conclusions}

The study however revealed the fact that incentives as driving force did carry as much weight as concern and driving force in terms of affecting the approach to work of the respondents. The study sought to show the impact of the above stated variables on the behavior of the 
PROBLEMS

OF MANAGEMENT

IN THE $21^{\text {st }}$ CENTURY

Volume 8, 2013

14

workers in Ghana Airport Company Limited. In particular, the study examined the impact of adequate incentives as motivational tool other than money in the effective functioning of the organization and offers suggestions for improvement.

This study was started and carried out on the premise that incentives especially financial incentive being a right of the worker is taken for granted however certain other factors would be needed to adequately motivate or satisfy the workers. Such factors include non monetary reward, free medical care, recognition, transportation and other incentives. Which became current after the study was conceived and started,

This position notwithstanding, it was possible to establish the importance of other factors in building the attitude of the workers. The findings of the study for example indicate that favouritism at the workplace is seen as sacrosanct in the past but now it is showing itself again and beginning to change the attitude of some workers, resulting in fear, tension, indiscipline, anxiety and frustration which at the end it might or can lead to low productivity.

The management of Ghana Airport will need to pay some attention to these other factors, which the data of this study have shown to be important. Every individual wants recognition and respect. The findings of this study point to the need for the management to recognize this. A recognition or appreciation of an effort made or a good job done is likely to produce even better job apart from making a happier and more satisfied worker as base on the research question such attitude from management can always influence workers approach to work and their performance. In instances that work is well done but attracts no comment, whereas the slightest mistake is condemned (negative stroking), then the likelihood is that more dissatisfied workers with less zeal or productivity for the job will be produced.

The study suggests that there is a sizeable discrepancy between actual practices of some advanced theories of motivation for workers. The reasons for such discrepancy can be traced to differences in organizational setting and culture, which was peculiar in Ghana. The study also suggests that no one statement about incentives at work can apply at all times or to all circumstances. The study tends to show that creation of a stimulating, productive and satisfying work environment could be beneficial for both the management and workers if the honest concern is shown for all parties involved. There is no short cut to it than getting the management committed to its success. As a first step, managers at various departments should examine themselves and be clear in their minds what they want, and what their own roles should be in the organizational setting. Furthermore, managers should be sensitive to variation in employee's need, abilities and traits and not applying a blanket treatment, not nepotisms or sectionalism to any work.

Alongside, a monetary incentive is another key factor in motivating employees. If the company aims at attaining organizational effectiveness, then they need to provide the employees what they deserve and be given other incentives that will ginger their morale to work. Elke and Zwick (2008) also suggest that monitory incentives is not the main thing in boosting productivity.

\section{Recommendations}

This study revealed that the workers motivational processes in Ghana Airport Company Limited have undergone tremendous change since the organization was established. The seeming delay of workers' wages and salaries would appear to have greatly affected the workers morale to perform as it is everywhere in Ghana. Under such a condition, workers cannot give their best and expected return or output from the job. The management would now need to take an urgent step to look into the problem if the employee is to achieve her stated objectives. Because of the study, it has been established that incentives really have some kind of influence on the workers. 
Immediate steps should be taken by management to make workers re-establish confidence in the new administrative system so as to restore or raise the morale of the employee. All the necessary equipment needed for the job. The level of commitment required of the workers calls for more incentives and other motivational solution. Based on the findings of this study, the following suggestions are offered for the future incentives that will be given to motivate employees:

1. The management of the Ghana Airport Company Limited should establish an adequate motivational unit in the company whose function will be to monitor and promote morale boosting activities in the company. Such a Unit should carry out studies on the welfare of the workers compare to similar organizations, and make their findings available for planning and implementation of reward system.

2. Staff development to enhance productivity and promote self fulfillment should be encouraged as a matter of deliberate policy;

3. There should be a searchlight on the leadership style in the organization and efforts should be made to promote only productive and effective workers. If this is to be achieved, appointment to leadership positions in the organization should weigh more towards capability of the staff that have attained the basic conditions, rather than on brotherly relationship or favouritism;

4. There is the need to always look out for talents for reward to serve as an incentive to others and create an aspiration for others to aim at

\section{References}

Cappelli, P., Neumark, D. (2001). Do high-performance work practices improve establishment-level outcomes? Industrial and Labor Relations Review, 54, 737-775.

Elke, W., \& Zwick, T. (2008). Reassessing the Productivity impact of employee involvement and financial incentives Retrieved from, http:/www.sbr-online.de/pdfarchive/einzelne_pdf/sbr_2008_ april-160-181.pdf

Gibbons, J. (2006). Employee engagement: A review of current research and its implications, conference board. Retrieved from, http://www.montrealoffice.wikispaces.com/file/view/ Employee+Engagement+-+Conference+Board.pdf

Heathfield, S. M. (2013). What Are incentives at work? Retrieved from, http://www.humanresources. about.com/od/employeerecognition/g/what-are-incentives-at-work.htm

James, I. J. (2011). Effective Motivation of Paraprofessional Staff in Academic Libraries in Nigeria. Library Philosophy and Practice, 1, 37.

McKinsey Quarterly Survey (2009). Economic conditions snapshot: Retrieved from, http://www.mckinsey.com/insights/economic_studies/economic_conditions_snapshot_june_2009_mckinsey_global_survey_results

Shanks, $\bar{H}$. N. (2012). Management and motivation. Retrieved from, http://www.jblearning.com/ samples/076373473x/3473x_ch02_4759.pdf

Zwick, T. (2004). Employee participation and productivity. Labour Economics, 11, 715-740.

Advised by Sonia Teresinha de Sousa Penin, University of Sao Paulo, Brazil

Received: October 28, 2013

Accepted: November 30, 2013

Godson Ahiabor

Lecturer, Department of Economics, Central University College, P. O. Box 2305, Tema-Ghana.

Phone: +233 244731219 .

E-mail: gkhiabor@yahoo.com 